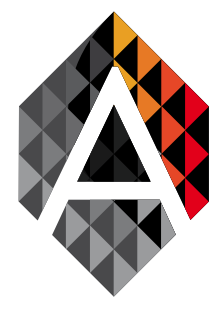

\title{
Stock Market Prediction Using Machine Learning(ML)Algorithms
}

\author{
M Umer Ghani ${ }^{\mathrm{a}}$, M Awais ${ }^{\mathrm{a}}$ and Muhammad Muzammul ${ }^{\mathrm{a}}$ \\ ${ }^{a}$ Department of Software Engineering, Government College University Faisalabad \\ umerghani92@gmail.com,muhammadawais@gcuf.edu.pk,m.muzammul275@gcuf.edu.pk
}

$\begin{array}{ll}\text { KEYWORD } & \text { ABSTRACT } \\
\begin{array}{ll}\text { Stock Market } & \text { Stocks are possibly the most popular financial instrument invented for building wealth } \\
\text { Prediction; } & \text { and are the centerpiece of any investment portfolio. The advances in trading technolo- } \\
\text { Machine } & \text { gy has opened up the markets so that nowadays nearly anybody can own stocks. From } \\
\text { Learning(ML); } & \text { last few decades, there seen explosive increase in the average person's interest for } \\
\text { Algorithms; } & \text { stock market. In a financially explosive market, as the stock market, it is important to } \\
\text { Linear } & \text { have a very accurate prediction of a future trend. Because of the financial crisis and re- } \\
\text { Regression; } & \text { cording profits, it is compulsory to have a secure prediction of the values of the stocks. } \\
\text { Exponential } & \text { Predicting a non-linear signal requires progressive algorithms of machine learning } \\
\text { Smoothing; } & \text { with help of Artificial Intelligence (AI). } \\
\text { Time Series } & \text { In our research, we are going to use Machine Learning Algorithm specially focus on } \\
\text { Forecasting } & \text { Linear Regression (LR), Three month Moving Average(3MMA), Exponential Smooth- } \\
& \text { ing (ES) and Time Series Forecasting using MS Excel as best statistical tool for graph } \\
& \text { and tabular representation of prediction results. We obtained data from Yahoo Finance } \\
& \text { for Amazon (AMZN) stock, AAPL stock and GOOGLE stock after implementation LR } \\
& \text { we successfully predicted stock market trend for next month and also measured accu- } \\
& \text { racy according to measurements. }\end{array} \\
\end{array}$

\section{Introduction}

Stock market is trading platform where different investors sale and purchase shares according to stock availability. Stock market ups and downs effects the profit of stakeholders. If market prices going up with available stock then stakeholders get profit with their purchased stocks. In other case, if market going down with available stock prices then stakeholders have to face losses. Buyers buy stocks with low prices and sell stocks at high prices and try to get huge profit. Similarly, sellers sell their products at high prices for profit purpose (Tae Kyun Lee et al, 2019). Stock market (SM) work as trusty platform among sellers and buyers. Advances in Artificial Intelligence (AI) supporting a lot in each field of life with its intelligent features. Several algorithms present in AI that performing their role in future predictions (Eunsuk Chong et al, 2017). Machine learning (ML) is a field of artificial intelligence (AI) that can be considered as we train machines with data and analysis future with test data. Machines can be trained on the basis of some standard that are called algorithms. Stock market predictions can be great beneficial to businessman. SMP provide future trend of stock prices on the basis of previous history (Bruno et al,2019). If stakeholders get future predictions then investment can lead him toward profit. Predictions can be $50 \%$ correct and $50 \%$ wrong as it is risk of business. Risks facing capability in business filed can

ADCAIJ: Advances in Distributed Computing and Artificial Intelligence Journal Regular Issue, Vol. 8 N. 4 (2019), 97-116 elSSN: 2255-2863 - http://adcaij.usal.es Ediciones Universidad de Salamanca - CC BY NC DC 
lead toward success. In any field of life, we take risks for success. Similarly, we rely on ML predictions about future prices of stock. In this chapter we would like to explain these ML algorithms with the help of their working methodologies and examples (Thomas Fischer et al, 2018). Before working on actual problem SMP, complete understanding of ML algorithms role in prediction is also necessary. That's why in this chapter we explained complete working scenario and problem definition (Bruno et al, 2019).Several Machine learning algorithms can be used for stock market prediction but in this research we used few algorithms like Linear regression (LR), Three Months Moving Average (3MMA) and Exponential Smoothing and if we further consider many other algorithms can also be used for Stock Market Prediction(SMP) (Bruno et al, 2019).

\subsection{Data Analysis (DA) and Stock Prediction (SP)}

Data analysis (DA) in machine learning (ML) is a process of applying technical skills (ML Algorithms) on historical data to obtain statistical as well as tabular results about predictions. It also considered as technical process of data illustration and evaluation. Two authors (Shamoo et al,2012; Resnik et al ,2013) explained about DA, according to their theory DA is process of distinguishing signals for decision making with statistical fluctuation of results. DA also included collection as well as analyzing process, it can be iterative according to problem statement. Several statistical techniques implemented in DA. Data scientists find patterns of entire data with special observations. Several types of quantitative as well as qualitative approaches as content analysis, history analysis, sentimental analysis and bibliographic analysis involved in DA (Tae Kyun Lee et al, 2019). DA study formulate predictions on the basis of historical data that can be present in form of notes, files, documents, tables, audio or video tapes. Accurate analysis of different research findings can lead to valid knowledge discovery. Inaccurate statistical presentation of data destroys the research findings of any scientist and guide wrong destinations to readers (Shepard, 2002) and public perceptions about research also influenced negatively (Bruno et al,2019). Integrity and accuracy are two main parts of statistical data analysis. In this research we used several data resources in form of datasets, research theories and financial resources of data presentation. Yahoo Finance, Quandle, Kaggle and several other similar platforms provided data that is used in stock market predictions. We obtained data from these platforms for different stock exchange companies and after applying ML algorithms we presented stocks predictions results statistically (Ben Moews et al, 2019).

\subsection{Introduction to stock market}

Stock market can be defined as combined platform of several markets and exchangers with regular process of buying and selling goods that shares issued publically (Comparison analysis performed at public platform). At this platform several situational financial performed for formal exchange process under defined rules and regulations (Hiransha et al, 2018). Multiple stocks trading places can be available at different place in a country where transections on stocks can be performed. There are two different terms used in stock market definition as stock exchange and stock market with consideration of formal trade assets. We can define stock market as, if someone is part of stock market will be considered as stock market trader, as he buy or sell his shares on one or different stocks (Ben Moews et al, 2019). Several stock exchange markets available at national as well as international level including Pakistan and world level biggest stock market i.e. New York Stock Exchange (NYSE), Chicago (CBOE) both of these are considered as national stock markets of USA (Tae Kyun Lee et al, 2019).

\subsection{Introduction to stock market trend analysis}

Trend is considered as direction of stock movement that is totally based on stock market ups and downs. Continues movement of stock in any direction upward or downward for specified duration or time period can be considered as trend. In stock market prediction trend analysis at current stage support a lot in future trend prediction (Thomas Fischer et al, 2018). Trend growing analysis for continues interval of time can be considered as future grow or continues down in trending market share prices can be supportive for future predictions as down. Stock market prediction always based on big amount of historical data analysis. Similarly trends also based on big data analysis results. Prediction about future trends in any stock market cannot be considered as $100 \%$ accurate. Trends presence in share market place provide predictions about trends in stock market. Gaining

M Umer Ghani, M Awais and Muhammad Muzammul

Stock Market Prediction Using Machine Learning(ML)Algorithms
ADCAIJ: Advances in Distributed Computing and Artificial Intelligence Journal Regular Issue, Vol. 8 N. 4 (2019), 97-116 eISSN: 2255-2863 - http://adcaij.usal.es Ediciones Universidad de Salamanca - CC BY NC DC 
in profit always based on trends, if investors move according to trend directions, they can be succeeded in their trade marketing (Bruno et al, 2019).

\subsection{Problem Statement}

Everyone want to be rich in his life with low efforts and great advantages. Similarly, we want to look in our future with inner most desire as we do not want to take risks or we want to decrease risk factor. Stock market is a place where selling and purchasing can provide future aims of life (Kang Zhang et al, 2019). Now the question is that how we can get advantages from stock market? Or what are the steps that can give us stocks market predictions before taking yourself in risk zoon (Yue-gang Song et al, 2018). How Artificial Intelligence with Machine learning algorithms can be supportive for future market trend predictions?

\subsection{Stock Market Prediction (SMP)}

If stock market trend predicted then we can avoid wastage of money. SMP is a process of predicting future on the base of past data. Prediction decreases the risk level to investors and increases the confidence level for investment. If they predicted goals before reach then they can avoid loss of money. All these consideration work as SMP. On the basis of historical data trends, we guess future trend that is called SMP(Changju Lee et al, 2019).

\section{Material and Methods}

$\mathrm{AI}$ is an intelligent field of latest research which is providing great help in solution of real time existing problems. AI supporting in each field of life as we use it in data processing in ATM machines, Bank accounts, Airways services, Reservation, X-RAYS, Auto door opening, recognition-based devices and weather forecasting. In other word we can say AI made our life easier and we can predict future. Earning money is major issue to face society and rick people considered as role models everywhere (Ben Moews et al, 2019). Stock market investments polices supported a lot in this process(Yue-gang Song et al, 2018). Stock market provide great benefits to intelligent investors but foolish investor's do not get much advantages form stock market. Why I said foolish? There is a big reason behind this, they invest in stock market without predicting future trend analysis of stocks ups/downs, that repel them in darky night. Some investors follow stock market predictions rules and enjoy great profits. Several tools support in stock market predictions as python, Java, Rstudio with R programming and Python programming as well (Wang Qili et al, 2018). Mostly predictions based on ML algorithms that are also used in these tools. Some famous prediction algorithms that are supported by several tools as well as programming languages are Regression (Linear, Logistic), K-Nearest Neighbor (KNN), Decision Tree (DT), Artificial Neural Network (ANN) and Simple Moving Average (SMA) with the help of Time Series Forecasting (TSF). In this research, we applied these ML algorithms on different stock datasets obtained for GOOGLE, FB, AMAZON and some other companies (Thomas Fischer et al, 2018). We predicted results by Rstudio and Excel sheets by using statistical as well as graphical presentation of results. After obtaining results by different predictors and ML techniques we performed comparison analysis to argue about best considerations. Several Machine learning algorithms can be used for stock market prediction but in this research we used few algorithms like Linear regression(LR), Three Months Moving Average(3MMA) and Exponential Smoothing and if we further consider many other algorithms can also be used for Stock Market Predic-tion(SMP).In Whole research we found Exponential Smoothing predictions results are best rather than Linear Regression(LR) and Three Months Moving Average(3MMA) (Bruno et al, 2019) .

\subsection{Machine Learning (ML) algorithms Implementation for Stocks Prediction}

We will implement machine learning algorithms on above explained datasets and we will also analyses the trends of data manipulation as combined analysis of GOOGLE, FB,AMAZON,AAPLE data. Mostly data is obtained from yahoo finance (FengmeiYang et al, 2019).

M Umer Ghani, M Awais and Muhammad Muzammul

Stock Market Prediction Using Machine Learning(ML)Algorithms
ADCAIJ: Advances in Distributed Computing and Artificial Intelligence Journal Regular Issue, Vol. 8 N. 4 (2019), 97-116 eISSN: 2255-2863 - http://adcaij.usal.es Ediciones Universidad de Salamanca - CC BY NC DC 
Table 1:. Amazon Data representation from Jan 2019 to July 2019

\begin{tabular}{|c|c|c|c|c|c|}
\hline Date & Open & High & Low & Close & Volume \\
\hline $\mathbf{1 / 2 / 2 0 1 9}$ & 1465.2 & 1553.36 & 1460.93 & $\mathbf{1 5 3 9 . 1 3}$ & 7983100 \\
\hline $\mathbf{1 / 3 / 2 0 1 9}$ & 1520.01 & 1538 & 1497.11 & $\mathbf{1 5 0 0 . 2 8}$ & 6975600 \\
\hline $\mathbf{1 / 4 / 2 0 1 9}$ & 1530 & 1594 & 1518.31 & $\mathbf{1 5 7 5 . 3 9}$ & 9182600 \\
\hline $\mathbf{1 / 7 / 2 0 1 9}$ & 1602.31 & 1634.56 & 1589.19 & $\mathbf{1 6 2 9 . 5 1}$ & 7993200 \\
\hline $\mathbf{1 / 8} / \mathbf{2 0 1 9}$ & 1664.69 & 1676.61 & 1616.61 & $\mathbf{1 6 5 6 . 5 8}$ & 8881400 \\
\hline $\mathbf{1 / 9} / \mathbf{2 0 1 9}$ & 1652.98 & 1667.8 & 1641.4 & $\mathbf{1 6 5 9 . 4 2}$ & 6348800 \\
\hline $\mathbf{1 / 1 0 / 2 0 1 9}$ & 1641.01 & 1663.25 & 1621.62 & $\mathbf{1 6 5 6 . 2 2}$ & 6507700 \\
\hline $\mathbf{1 / 1 1 / 2 0 1 9}$ & 1640.55 & 1660.29 & 1636.22 & $\mathbf{1 6 4 0 . 5 6}$ & 4686200 \\
\hline- & - & - & - & - & - \\
\hline $\mathbf{7 / 2 5 / 2 0 1 9}$ & 2001 & 2001.2 & 1972.72 & $\mathbf{1 9 7 3 . 8 2}$ & 4136500 \\
\hline
\end{tabular}

\subsubsection{AMAZON(AMZN) data analysis and Stock market predictions with Machine Learning (ML)}

AMZN considered as huge stock market that attracts investors to buy/sell its shares and its becoming a trendy business market in the world.

\subsubsection{AMZN Data Representation and data ranges}

In this research we considered data from start of year as January 2019 to 25 July 2019 then we evaluated our approach with different prediction methodologies.

Amazon One Month Stock Data and Normalized Value

Table 2: July 2019 data for normalization (Amazon Yahoo Finance)

\begin{tabular}{|c|c|c|c|c|c|c|c|}
\hline Date & Open & High & Low & Close & Adj Close & Volume & Normalized \\
\hline $\mathbf{7 / 2 6 / 2 0 1 9}$ & 1942 & 1950.9 & 1924.51 & 1943.05 & 1943.05 & 4921900 & 0.96 \\
\hline $\mathbf{7 / 2 5 / 2 0 1 9}$ & 2001 & 2001.2 & 1972.72 & 1973.82 & 1973.82 & 4136500 & 0.98 \\
\hline $\mathbf{7 / 2 4 / 2 0 1 9}$ & 1969.3 & 2001.3 & 1965.87 & 2000.81 & 2000.81 & 2631300 & 0.99 \\
\hline $\mathbf{7 / 2 3 / 2 0 1 9}$ & 1995.99 & 1997.79 & 1973.13 & 1994.49 & 1994.49 & 2703500 & 0.99 \\
\hline $\mathbf{7 / 2 2 / 2 0 1 9}$ & 1971.14 & 1989 & 1958.26 & 1985.63 & 1985.63 & 2900000 & 0.98 \\
\hline $\mathbf{7 / 1 9 / 2 0 1 9}$ & 1991.21 & 1996 & 1962.23 & 1964.52 & 1964.52 & 3185600 & 0.97 \\
\hline $\mathbf{7 / 1 8 / 2 0 1 9}$ & 1980.01 & 1987.5 & 1951.55 & 1977.9 & 1977.9 & 3504300 & 0.98 \\
\hline $\mathbf{7 / 1 6 / 2 0 1 9}$ & 2010.58 & 2026.32 & 2001.22 & 2009.9 & 2009.9 & 2618200 & 0.99 \\
\hline $\mathbf{7 / 1 2 / 2 0 1 9}$ & 2008.27 & 2017 & 2003.87 & 2011 & 2011 & 2509300 & 1.00 \\
\hline $\mathbf{7 / 1 1 / 2 0 1 9}$ & 2025.62 & 2035.8 & 1995.3 & 2001.07 & 2001.07 & 4317800 & 0.99 \\
\hline $\mathbf{7 / 1 0 / 2 0 1 9}$ & 1996.51 & 2024.94 & 1995.4 & 2017.41 & 2017.41 & 4931900 & 1.00 \\
\hline
\end{tabular}

M Umer Ghani, M Awais and Muhammad Muzammul Stock Market Prediction Using Machine Learning(ML)Algorithms
ADCAIJ: Advances in Distributed Computing and Artificial Intelligence Journal Regular Issue, Vol. 8 N. 4 (2019), 97-116 elSSN: 2255-2863 - http://adcaij.usal.es Ediciones Universidad de Salamanca - CC BY NC DC 


\begin{tabular}{|c|c|c|c|c|c|c|c|}
\hline Date & Open & High & Low & Close & Adj Close & Volume & Normalized \\
\hline $\mathbf{7 / 9 / 2 0 1 9}$ & 1947.8 & 1990.01 & 1943.48 & 1988.3 & 1988.3 & 4345700 & 0.98 \\
\hline $\mathbf{7 / 8 / 2 0 1 9}$ & 1934.12 & 1956 & 1928.25 & 1952.32 & 1952.32 & 2883400 & 0.97 \\
\hline $\mathbf{7 / 5 / 2 0 1 9}$ & 1928.6 & 1945.9 & 1925.3 & 1942.91 & 1942.91 & 2628400 & 0.96 \\
\hline $\mathbf{7 / 3 / 2 0 1 9}$ & 1935.89 & 1941.59 & 1930.5 & 1939 & 1939 & 1690300 & 0.96 \\
\hline $\mathbf{7 / 2 / 2 0 1 9}$ & 1919.38 & 1934.79 & 1906.63 & 1934.31 & 1934.31 & 2645900 & 0.96 \\
\hline $\mathbf{7 / 1 / 2 0 1 9}$ & 1922.98 & 1929.82 & 1914.66 & 1922.19 & 1922.19 & 3203300 & 0.95 \\
\hline
\end{tabular}

We obtained data from yahoo finance for AMZN stocks prediction. We applied normalization process on data and obtained values that are present in right corner of Table 2. Normalization is considered as ratio between close prices and maximum close prices. If we see the maximum close prices in Table 2 is 2020.99. We divided all close prices by maximum close price and obtained normalized column.

\subsubsection{Graphical representation of Amazon trend analysis}

Trends according to date can be checked about any product that is part of stock market. For this analysis we drawn graph between open/high/low/close prices. We can check how prices are moving day by day. Instead of complete study of data graph can give fully analytical view of market trends. Market always remain in changing process and statistical analysis give entire data outlook without any complexities.

AMZN

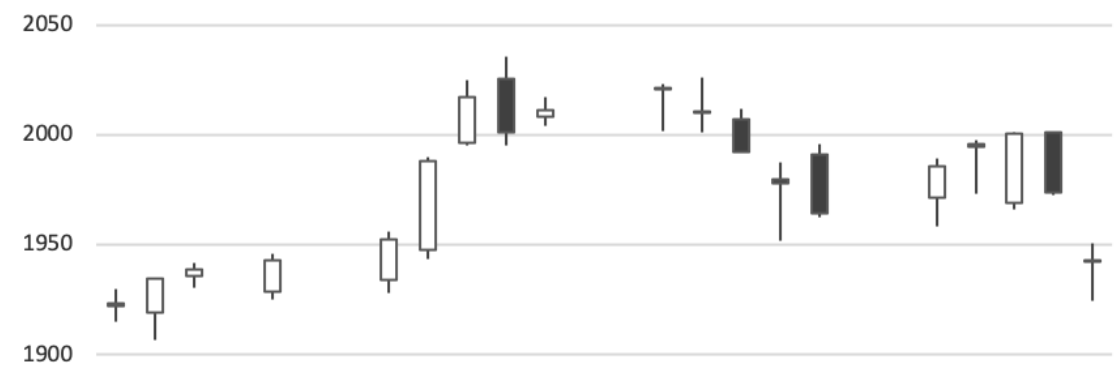

1850

1800

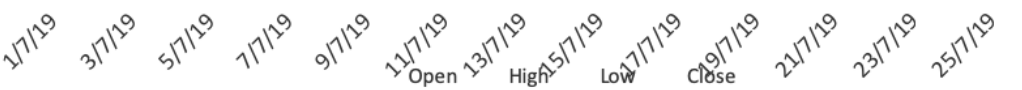

Figure 1: Graphical representation of AMZN Stock market trends.

Graph is representing a trend pattern where central dates of month showing high values. At start of month prices trend slow with central part of month it raises to high and at end of moth its showing medium rate of price changings Fig2.

M Umer Ghani, M Awais and Muhammad Muzammul Stock Market Prediction Using Machine Learning(ML)Algorithms
ADCAIJ: Advances in Distributed Computing and Artificial Intelligence Journal Regular Issue, Vol. 8 N. 4 (2019), 97-116 elSSN: 2255-2863 - http://adcaij.usal.es Ediciones Universidad de Salamanca - CC BY NC DC 


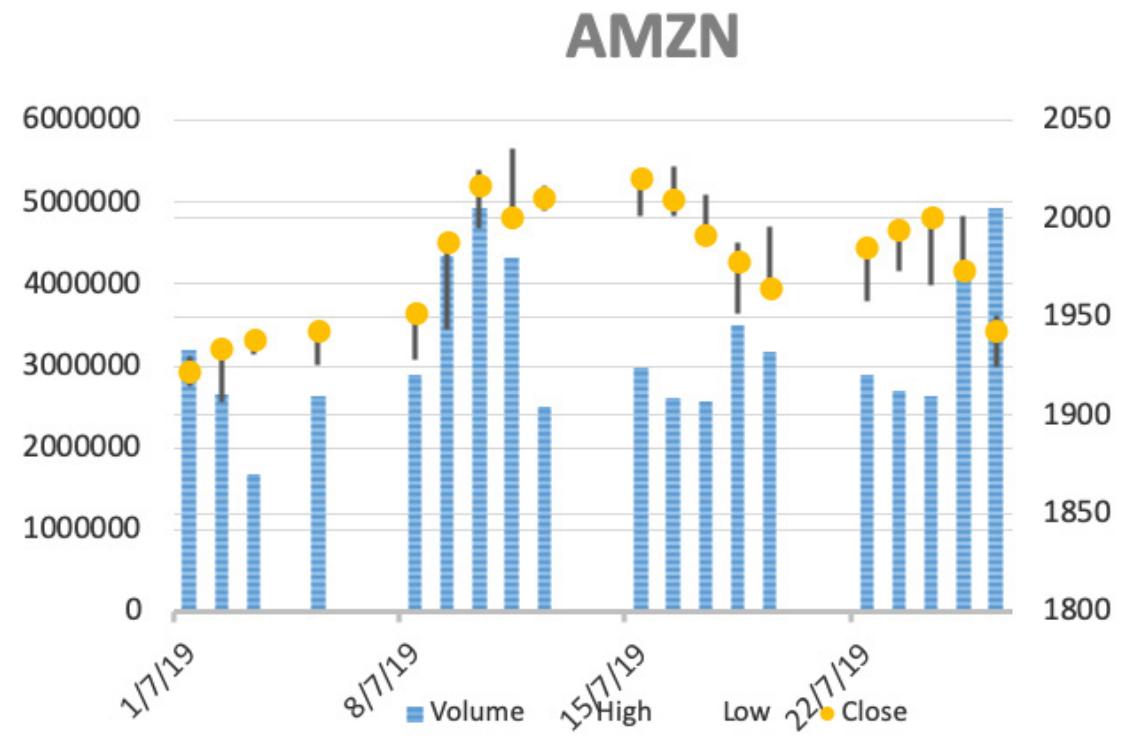

Figure 2: Amazon trend analysis graph with data adjustments.

\subsection{Linear Regression (LR) introduction as ML algorithm}

These algorithms can be understood easily and can be implemented easily. This algorithm runs into risky and over fitting environment easily. In some cases these algorithms are considered very much simple to solve complex problems. Linear regression runs under the relationship of two variables as one variable considered and dependent variable and other is considered as explanatory variable. A linear regression line has an equation of the form equation $\mathrm{Y}=\mathrm{a}+\mathrm{bX}$, where $\mathrm{X}$ is the explanatory variable and $\mathrm{Y}$ is the dependent variable. The slope of the line is $\mathrm{b}$, and $\mathrm{a}$ is the intercept (the value of $\mathrm{y}$ when $\mathrm{x}=0$ ) by (Vineet Maheshwari et al ,2019).

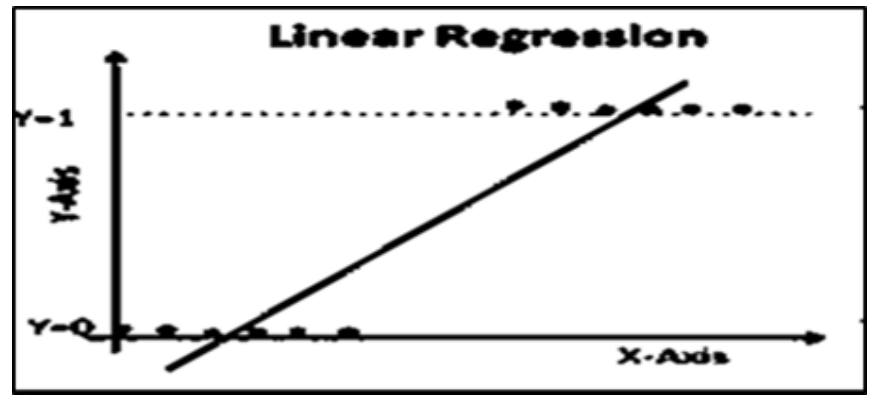

Figure 3: Linear regression/Logistic regression representation.

\subsubsection{Linear Regression (LR) implementation for AMZN stock prediction}

Linear regression is used for predictions with data that has numeric target variable. During prediction we use some variables as dependent variables and few considered as independent variables. In situation when there is one dependent and one independent variable, we prefer to use linear regression methodologies. Regression can be single variable or multi variable, it depends upon situation named as single variable or multi variable regression (FengmeiYang et al, 2019). Here in stock market prediction process, we have one date variable and one closing price variable. Closing price variable is our independent variable which also be considered as target variable. In this processing we will generate a prediction equation using liner regression method. We will generate prediction as $\mathbf{y}=\mathbf{c}+\mathbf{b x}$, then we can say ' $\mathrm{Y}$ ' is our predicted stock price and $\mathrm{x}$ is actual price.

M Umer Ghani, M Awais and Muhammad Muzammul Stock Market Prediction Using Machine Learning(ML)Algorithms
ADCAIJ: Advances in Distributed Computing and Artificial Intelligence Journal Regular Issue, Vol. 8 N. 4 (2019), 97-116 elSSN: 2255-2863 - http://adcaij.usal.es Ediciones Universidad de Salamanca - CC BY NC DC 


\section{Regression model based one 7 moths historical data}

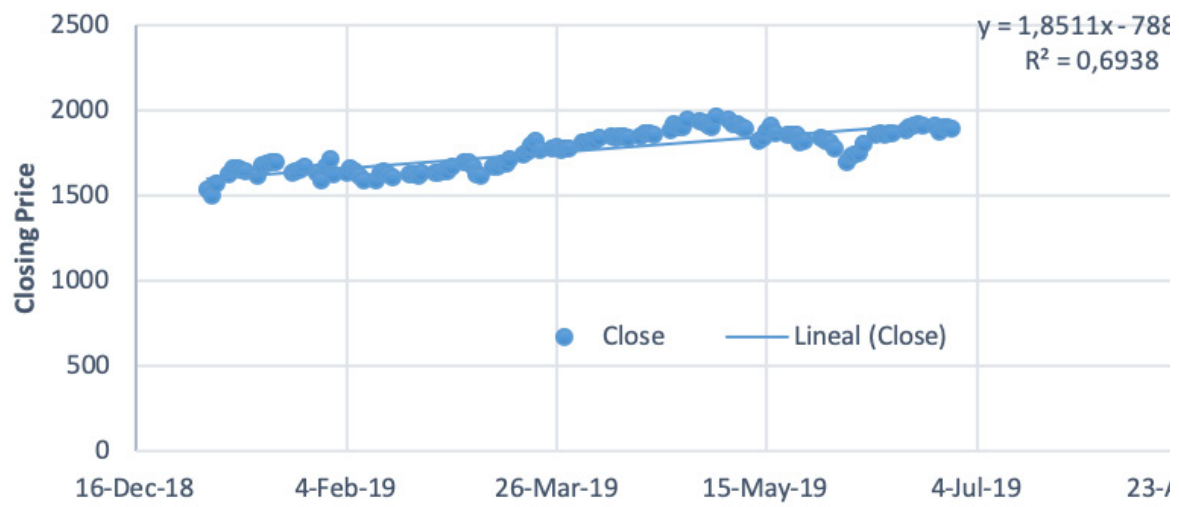

Figure 4: Regression Line for historical data of closing prices with respect to date.

In Fig4, linear regression line drawn between date and historical closing prices from Jan 2019 to July 2019. When we used linear regression graph in MS Excel it given us an equation, where ' $\mathrm{Y}$ ' representing predicted value and ' $\mathrm{X}$ ' represents actual value. By using this equation, we can predict future stock prices.

\section{Linear Regression Equation $\quad Y=1.8511 X-78860 \quad$ Eq1

$$
R^{2}=0.6938
$$

$\mathrm{R}^{2}$ represents root mean square error that is considered as classification error, we can say $0.6 \%$ classification performed wrongly by linear regression and remaining working is correct and error free. In this processing data of closing prices from Jan 2019 to July 2019 used. We considered only date and closing prices for prediction. Equation 1 is our prediction with respect to actual values. By using this equation, we can predict next month closing prices that can be great beneficial to stockiest. Now let us consider predictions based on linear regression and generated data.

Table 3: Linear regression classification for stock market prediction

\begin{tabular}{|c|c|c|c|c|c|}
\hline JULY & Actual Prices & Predicted Prices & ABS Error & Error^2 $^{\wedge}$ & \% Error \\
\hline 1-Jul-19 & 1922.19 & $1,934.96$ & 12.77 & 163.12 & $0.66 \%$ \\
\hline 2-Jul-19 & 1934.31 & $1,936.81$ & 2.50 & 6.26 & $0.13 \%$ \\
\hline 3-Jul-19 & 1939.00 & $1,938.66$ & 0.34 & 0.11 & $0.02 \%$ \\
\hline $\mathbf{2 5 - J u l - 1 9}$ & 1973.82 & $1,979.39$ & 5.57 & 31.00 & $0.28 \%$ \\
\hline & & Average $=$ & $\mathbf{2 4 . 3 1}$ & $\mathbf{1 0 6 5 . 0 3}$ & $\mathbf{1 \%}$ \\
\hline & & & MAD & MSE & MAPE \\
\hline & & r-square= & 0.6938 & & \\
\hline & & $\mathbf{r}=$ & -0.83295 & & \\
\hline
\end{tabular}

Now let's consider Table 3 for prediction explanation, In this table we considered July as our actual data. When we used this data there was only date and closing actual price columns were present. We used linear regression curve to obtain all other columns of table and predicted values. In this Table predicted values based on equation 1, we used MS Excel for the purpose of our statistical as well as linear regression prediction analysis.

M Umer Ghani, M Awais and Muhammad Muzammul Stock Market Prediction Using Machine Learning(ML)Algorithms
ADCAIJ: Advances in Distributed Computing and Artificial Intelligence Journal Regular Issue, Vol. 8 N. 4 (2019), 97-116 elSSN: 2255-2863 - http://adcaij.usal.es Ediciones Universidad de Salamanca - CC BY NC DC 


\subsubsection{Graphical representation of actual and predicted prices by line graph}

\section{AMAZON ONE MONTH ACTUAL AND PREDICTED PRICES}

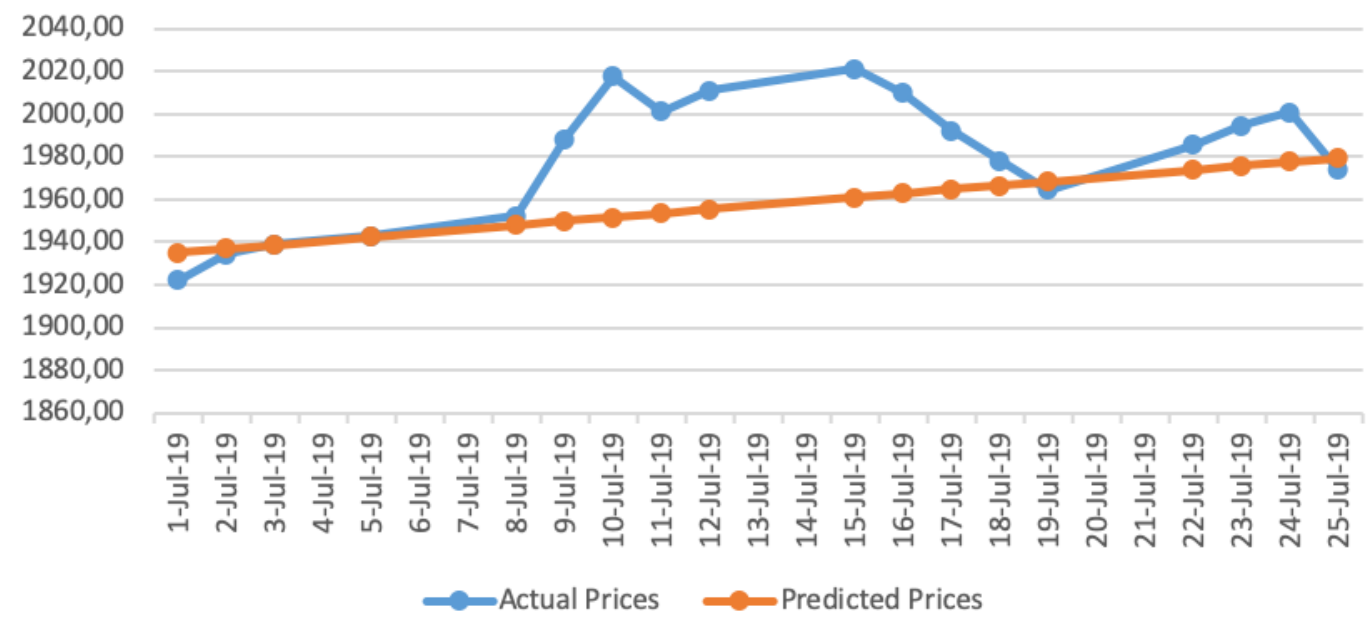

Figure 5: Line graph between actual and predicted prices with respect to date.

There can be different types of error present in our predictions that are explained by Table 3 .

- Absolute Error: If we want to calculate absolute error in our prediction we can perform calculations by predicted values-actual close prices. In MS Excel it can be calculated by following formula

\section{ABS Error $=F x=a b s($ forcast-actual $)$}

Similarly, we can calculate other types of errors in our predictions

- Square Error: It can be defined as sqare of absolute error=(ABS ERRR $)^{2}$

- \%age Error: When absolute error is divided by actual close then we obtain percentage error

$\%$ Error $=$ ABS Error/Actual Close price

- Average absolute error=Mean absolute deviation=MAD

- Average square error=Mean of square error=MSE

- Average percentage error $=$ Mean absolute \%age error $=$ MAPE

As r-square is 0.6938 , this represents root square value or it can be said as variability in closing prices of AMZN stock market.

- $\mathrm{R}$-value is $-\mathrm{ve}$ squawroot of $\mathrm{r}$-square $=\mathrm{r}=-0.8329$

When size of data increases the accuracy of results also increases. Here we used only seven months data for predictions on the basis of regression equation. If we check only one-month data on the basis of linear regression, there will be large amount of variability and all types of error will increase.

\subsubsection{Linear Regression based on One-month AMMZ Stock data}

Here we used only June month data to draw linear regression curve, we can see all types of error values increases. We can say as SIMPLE size will be larger the prediction results will be accurate and vice versa.

M Umer Ghani, M Awais and Muhammad Muzammul Stock Market Prediction Using Machine Learning(ML)Algorithms
ADCAIJ: Advances in Distributed Computing and Artificial Intelligence Journal Regular Issue, Vol. 8 N. 4 (2019), 97-116 eISSN: 2255-2863 - http://adcaij.usal.es Ediciones Universidad de Salamanca - CC BY NC DC 


\section{Regression Model based on one month data}

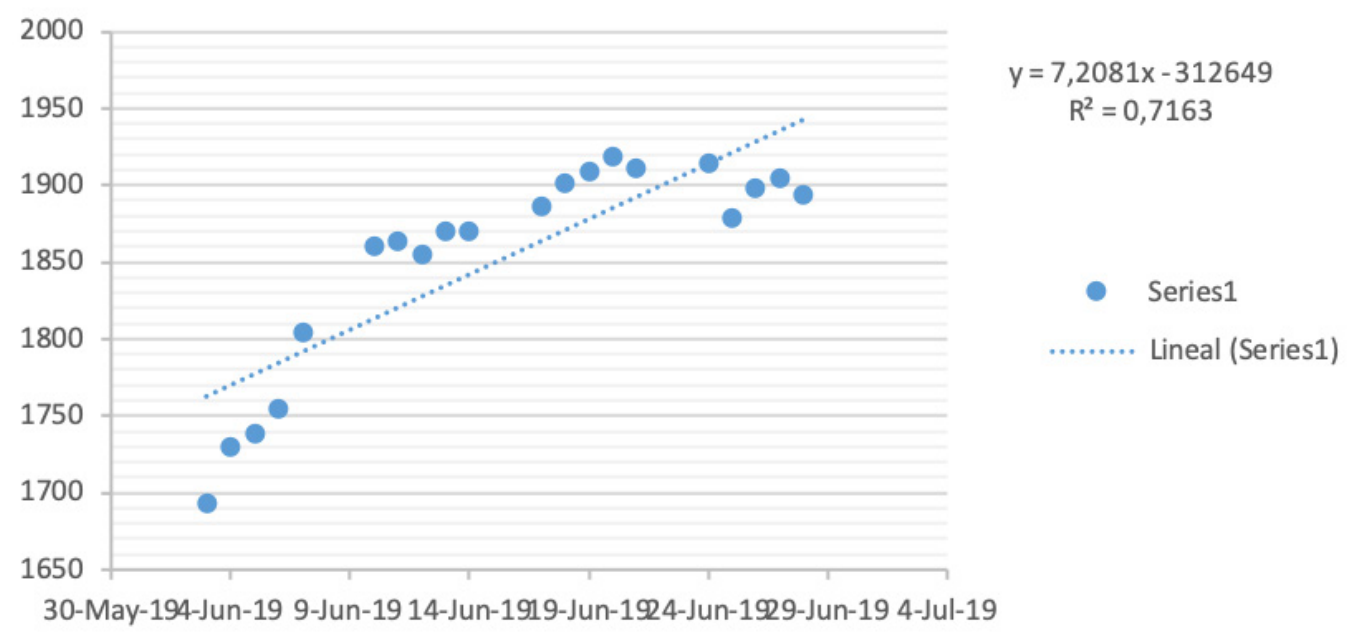

Figure 6: Regression equation generated on one month data as on JUNE.

Table 4: Predictions based on one-month regression line for AMZN Stock

\begin{tabular}{|c|c|c|c|c|c|}
\hline JULY & Actual Prices & Predicted Prices & ABS Error & Error $^{\wedge} 2$ & $\%$ Error \\
\hline 1-Jul-19 & 1922.18994 & $1,962.94$ & 40.75 & 1660.62 & $2.12 \%$ \\
\hline 2-Jul-19 & 1934.31006 & $1,970.15$ & 35.84 & 1284.42 & $1.85 \%$ \\
\hline 3-Jul-19 & 1939 & $1,977.36$ & 38.36 & 1471.25 & $1.98 \%$ \\
\hline 5-Jul-19 & 1942.91003 & $1,991.77$ & 48.86 & 2387.60 & $2.51 \%$ \\
\hline 8-Jul-19 & 1952.31995 & $2,013.40$ & 61.08 & 3730.46 & $3.13 \%$ \\
\hline 10-Jul-19 & 2017.41003 & $2,027.81$ & 10.40 & 108.23 & $0.52 \%$ \\
\hline 15-Jul-19 & 2020.98999 & $2,063.85$ & 42.86 & 1837.33 & $2.12 \%$ \\
\hline 16-Jul-19 & 2009.90002 & $2,071.06$ & 61.16 & 3740.81 & $3.04 \%$ \\
\hline 17-Jul-19 & 1992.03003 & $2,078.27$ & 86.24 & 7437.38 & $4.33 \%$ \\
\hline 18-Jul-19 & 1977.90002 & $2,085.48$ & 107.58 & 11573.11 & $5.44 \%$ \\
\hline 19-Jul-19 & 1964.52002 & $2,092.69$ & 128.17 & 16426.65 & $6.52 \%$ \\
\hline 22-Jul-19 & 1985.63001 & $2,114.31$ & 128.68 & 16558.75 & $6.48 \%$ \\
\hline 23-Jul-19 & 1994.48999 & $2,121.52$ & 127.03 & 16136.34 & $6.37 \%$ \\
\hline 24-Jul-19 & 2000.81006 & $2,128.73$ & 127.92 & 16362.74 & $6.39 \%$ \\
\hline \multirow[t]{5}{*}{ 25-Jul-19 } & 1973.81995 & $2,135.94$ & 162.12 & 26281.32 & $8.21 \%$ \\
\hline & & Average: & 72.47 & 7231.59 & $4 \%$ \\
\hline & & & MAD & MSE & MAPE \\
\hline & & r-square $=$ & 0.7163 & & \\
\hline & & $\mathrm{r}=$ & -0.84635 & & \\
\hline
\end{tabular}

ADCAIJ: Advances in Distributed Computing and Artificial Intelligence Journal Regular Issue, Vol. 8 N. 4 (2019), 97-116 eISSN: 2255-2863 - http://adcaij.usal.es Ediciones Universidad de Salamanca - CC BY NC DC 
Here we can compare the results of Table 3 and Table4, the values of error percentage increases from $1 \%$ to $4 \%$ that is prove of our argument. In other words, we can say as SAMPLE size increases the chances of errors in predictions decreases.

If we want to improve accuracy in our predictions there are two more linear regression techniques that supportively work to decrease variability in actual and predicted values of closing prices. If we check Fig5, there is less symmetry between actual and predicted stock price line. The amount of variability in actual and predicted values of stock prices indicate accuracy of classifier. Let's decrease variability and increase accuracy by following methods.

\subsubsection{Stocks prediction using 3-month average measurements (AMZN)}

Table 5: AMZN stock prediction using 3-month average method

\begin{tabular}{|c|c|c|c|c|c|}
\hline JULY & Actual Prices & Predicted Prices & ABS Error & $\operatorname{Error}^{\wedge} 2$ & $\%$ Error \\
\hline 26-Jun-19 & 1897.83 & & & & \\
\hline 27-Jun-19 & 1904.28 & & & & \\
\hline 28-Jun-19 & 1893.63 & & & & \\
\hline 1-Jul-19 & 1922.19 & $1,898.58$ & 23.61 & 557.43 & $1.23 \%$ \\
\hline 2-Jul-19 & 1934.31 & $1,906.70$ & 27.61 & 762.32 & $1.43 \%$ \\
\hline 3-Jul-19 & 1939.00 & $1,916.71$ & 22.29 & 496.84 & $1.15 \%$ \\
\hline 5-Jul-19 & 1942.91 & $1,931.83$ & 11.08 & 122.69 & $0.57 \%$ \\
\hline 8-Jul-19 & 1952.32 & $1,938.74$ & 13.58 & 184.41 & $0.70 \%$ \\
\hline 9-Jul-19 & 1988.30 & $1,944.74$ & 43.56 & 1897.19 & $2.19 \%$ \\
\hline 10-Jul-19 & 2017.41 & $1,961.18$ & 56.23 & 3162.19 & $2.79 \%$ \\
\hline 11-Jul-19 & 2001.07 & $1,986.01$ & 15.06 & 226.80 & $0.75 \%$ \\
\hline 15-Jul-19 & 2020.99 & $2,009.83$ & 11.16 & 124.62 & $0.55 \%$ \\
\hline 18-Jul-19 & 1977.90 & $2,007.64$ & 29.74 & 884.47 & $1.50 \%$ \\
\hline 19-Jul-19 & 1964.52 & $1,993.28$ & 28.76 & 826.95 & $1.46 \%$ \\
\hline 22-Jul-19 & 1985.63 & $1,978.15$ & 7.48 & 55.95 & $0.38 \%$ \\
\hline 23-Jul-19 & 1994.49 & $1,976.02$ & 18.47 & 341.26 & $0.93 \%$ \\
\hline 24-Jul-19 & 2000.81 & $1,981.55$ & 19.26 & 371.08 & $0.96 \%$ \\
\hline \multirow[t]{5}{*}{ 25-Jul-19 } & 1973.82 & $1,993.64$ & 19.82 & 392.97 & $1.00 \%$ \\
\hline & & Average & 21.08 & 609.22 & $1 \%$ \\
\hline & & & MAD & MSE & MAPE \\
\hline & & r-square $=$ & 0.6938 & & \\
\hline & & $r=$ & -0.83295 & & \\
\hline
\end{tabular}

In this method we used previous three days average to predict next day price. If we compare Table 3,4,5, It can be said the values of average absolute error decreases by 3 -month average regression method. The value of MAE in Table 3 was 24.31, in Table 4 was 74.47 but in Table 5 it is 21.08 that represents less error chances by using 3-month average method. Below is graphical representation of actual vs predicted closing prices that can be considered better prediction.

ADCAIJ: Advances in Distributed Computing and Artificial Intelligence Journal Regular Issue, Vol. 8 N. 4 (2019), 97-116 elSSN: 2255-2863 - http://adcaij.usal.es Ediciones Universidad de Salamanca - CC BY NC DC 


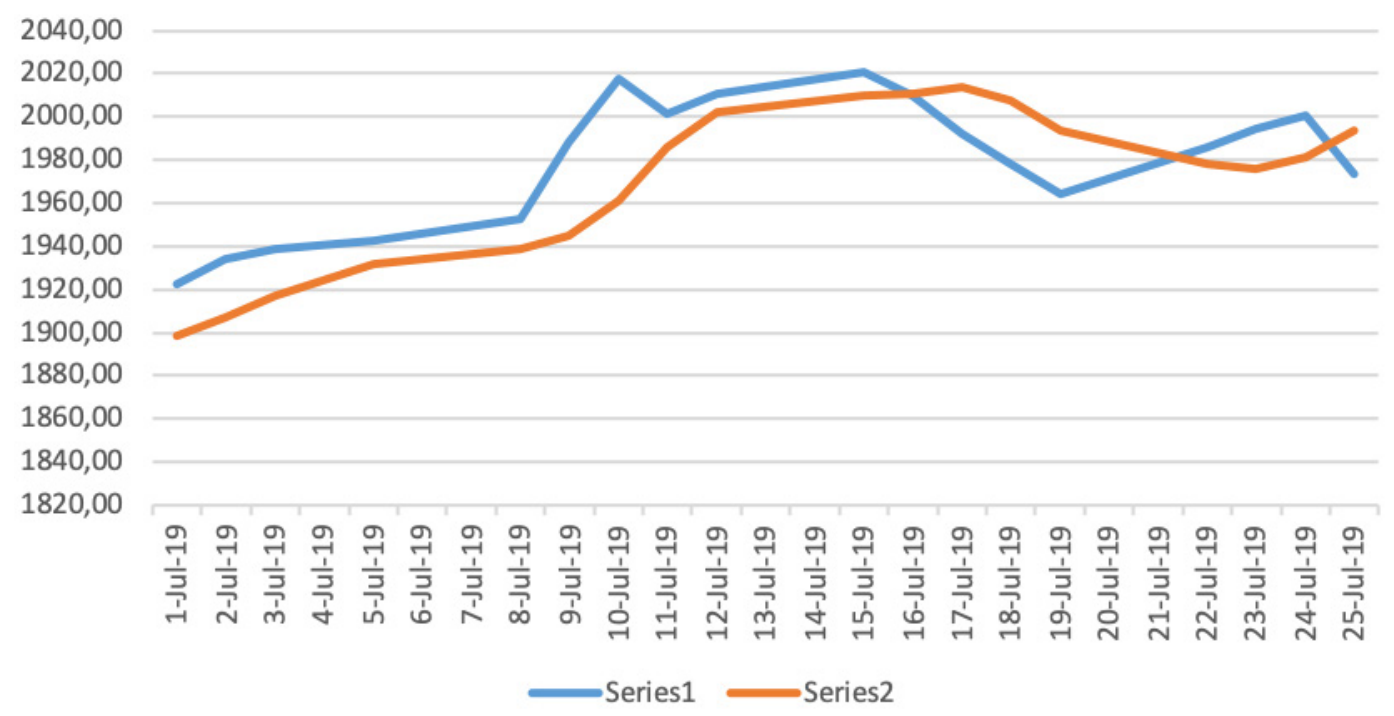

Figure 7: AMZN stock prediction using 3-month average method (Table 5).

Here in Fig7 blue line represents actual stock prices of AMZN products and orange line representing predicted closing prices of AMZN stocks. If we compare Fig 5 and Fig7 we can imagine about prediction accuracy.

\subsubsection{AMZN-Stock prediction using Exponential Smoothing method}

In this method we use an alpha value as alpha can be 0.4 or 0.8 then we consider first three close prices as seed values and from first three values central value considered as seed of prediction value, then we apply formula for prediction calculation.

Following formula work for exponential smoothing measurements

Prediction with exponential smoothing=

Exp smoothing=previous forcast + alpha* (actual value-forcast value)

For prediction test we change values according to need, first we put alpha $=0.4$ and check the values of error measures, then we place alpha $=0.8$ and the changings in errors measurements considered. Whole processing, we did in MS excel, let us consider data below for further explanation.

Table 6: AMZN stock prediction using exponential smoothing

\begin{tabular}{|c|c|c|c|c|c|}
\hline & alpha= & 0.8 & & & \\
\hline JULY & Actual Prices & Predicted Prices & ABS Error & Error^2 & \% Error \\
\hline 26-Jun-19 & 1897.83 & & & & \\
\hline 27-Jun-19 & 1904.28 & & & & \\
\hline 28-Jun-19 & 1893.63 & 1904.28 & & & $1.37 \%$ \\
\hline 1-Jul-19 & 1922.19 & $1,895.76$ & 26.43 & 698.54 & $0.90 \%$ \\
\hline 2-Jul-19 & 1934.31 & $1,916.90$ & 17.41 & 302.97 & $0.99 \%$ \\
\hline 17-Jul-19 & 1992.03 & $2,011.65$ & 19.62 & 385.08 & \\
\hline
\end{tabular}

M Umer Ghani, M Awais and Muhammad Muzammul Stock Market Prediction Using Machine Learning(ML)Algorithms
ADCAIJ: Advances in Distributed Computing and Artificial Intelligence Journal Regular Issue, Vol. 8 N. 4 (2019), 97-116 elSSN: 2255-2863 - http://adcaij.usal.es Ediciones Universidad de Salamanca - CC BY NC DC 


\begin{tabular}{|c|c|c|c|c|c|}
\hline & alpha= & 0.8 & & & \\
\hline JULY & Actual Prices & Predicted Prices & ABS Error & Error^2 & \% Error \\
\hline 19-Jul-19 & 1964.52 & $1,981.51$ & 16.99 & 288.69 & $0.86 \%$ \\
\hline 22-Jul-19 & 1985.63 & $1,967.92$ & 17.71 & 313.71 & $0.89 \%$ \\
\hline 23-Jul-19 & 1994.49 & $1,982.09$ & 12.40 & 153.82 & $0.62 \%$ \\
\hline 24-Jul-19 & 2000.81 & $1,992.01$ & 8.80 & 77.45 & $0.44 \%$ \\
\hline 25-Jul-19 & 1973.82 & $1,999.05$ & 25.23 & 636.55 & $1.28 \%$ \\
\hline & & Average & $\mathbf{1 6 . 6 2}$ & $\mathbf{3 6 3 . 8 3}$ & $\mathbf{1 \%}$ \\
\hline & & & MAD & MSE & MAPE \\
\hline & & r-square= & 0.6938 & & \\
\hline
\end{tabular}

Here in Table 6, we can check accuracy improvements absolute error value decreases up to 16.62 that is less from all other methods. In short, we can say the prediction values by exponential smoothing is best in results. Error accordance decreases in this method and as the value of errors decreases the accuracy of predicted results can be considered best.

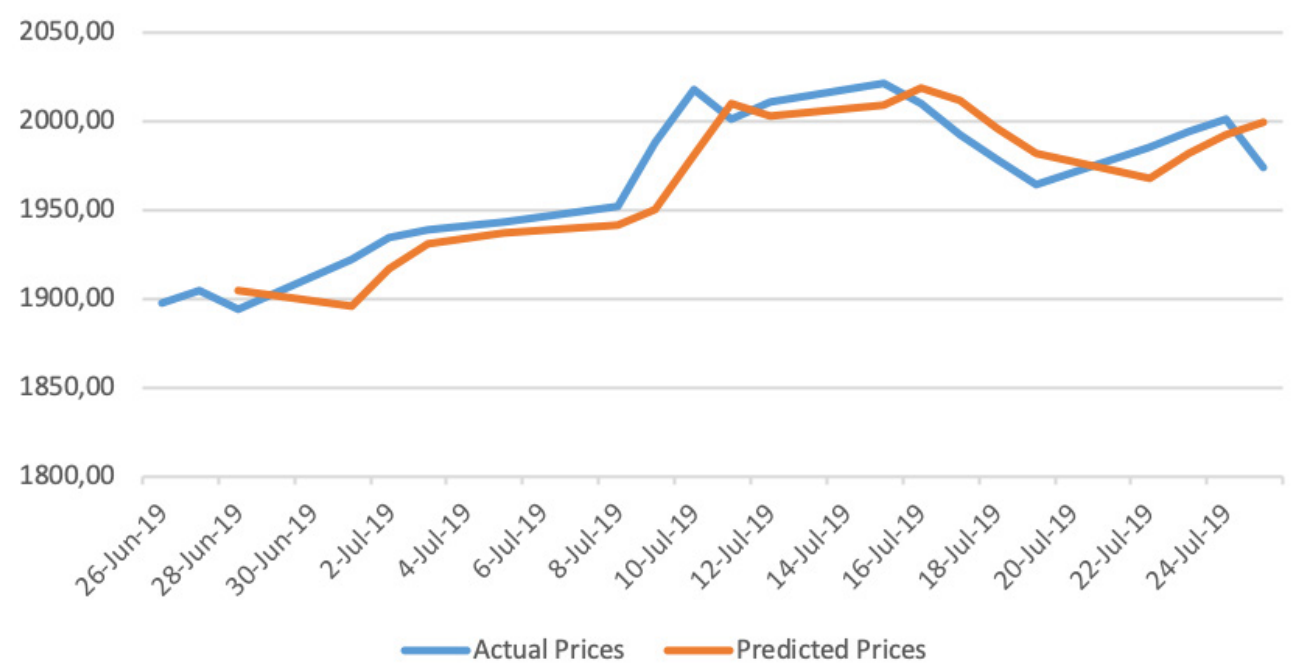

Figure 8: Exponential smoothing results for AMZN Stock prediction.

In this previous study we considered 3 different methods for stock prediction, firstly we considered linear regression and results were presented with 24.31 average absolute error, secondly we used only one month sample for linear regression equation then the value of average absolute error was 72.43 ,

Thirdly we used 3-month average regression methodology and obtained 21.08 average absolute error value, at last we used exponential smoothing measurements based on linear regression methodology and obtained 16.62 average absolute error values that was most significant results that were predicted on the basis of AMZN stock market data from yahoo finance market. At last we can say exponential smoothing proved its prediction best as the value of average absolute error was smallest than all others.

M Umer Ghani, M Awais and Muhammad Muzammul Stock Market Prediction Using Machine Learning(ML)Algorithms
ADCAIJ: Advances in Distributed Computing and Artificial Intelligence Journal Regular Issue, Vol. 8 N. 4 (2019), 97-116 elSSN: 2255-2863 - http://adcaij.usal.es Ediciones Universidad de Salamanca - CC BY NC DC 


\subsubsection{AMZN One-month prediction on the basis of linear regression equation}

\section{ONE Month prediction with LR-Model}

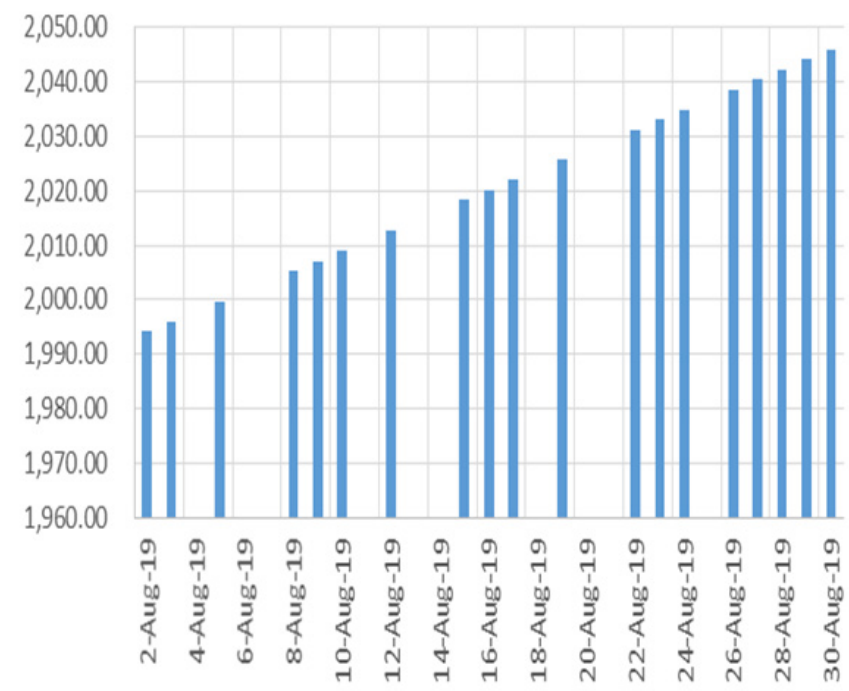

Figure 9: One-month prediction graph for AMZN Stocks.

After apply four different working methodologies we are able to predict next month prices of Amazon stock market, below is next month prediction as well as graphical representation of predicted prices. In linear regression equation we used seven months data as historical record and after generating equation we evaluated next month predictions.

Table 7: One-month prediction for AMZN Stock prices

\begin{tabular}{|c|c|}
\hline August & Predictedcloseprice \\
\hline 2-Aug-19 & $1,994.20$ \\
\hline 3-Aug-19 & $1,996.05$ \\
\hline 5-Aug-19 & $1,999.75$ \\
\hline 8-Aug-19 & $2,005.30$ \\
\hline 9-Aug-19 & $2,007.15$ \\
\hline 12-Aug-19 & $2,012.71$ \\
\hline 16-Aug-19 & $2,020.11$ \\
\hline 17-Aug-19 & $2,021.96$ \\
\hline 19-Aug-19 & $2,025.67$ \\
\hline 22-Aug-19 & $2,031.22$ \\
\hline 23-Aug-19 & $2,033.07$ \\
\hline 24-Aug-19 & $2,034.92$ \\
\hline
\end{tabular}

MUmer Ghani, M Awais and Muhammad Muzammul Stock Market Prediction Using Machine Learning(ML)Algorithms
ADCAIJ: Advances in Distributed Computing and Artificial Intelligence Journal Regular Issue, Vol. 8 N. 4 (2019), 97-116 elSSN: 2255-2863 - http://adcaij.usal.es Ediciones Universidad de Salamanca - CC BY NC DC 


\begin{tabular}{|c|c|}
\hline August & Predictedcloseprice \\
\hline 26-Aug-19 & $2,038.62$ \\
\hline 27-Aug-19 & $2,040.47$ \\
\hline 28-Aug-19 & $2,042.33$ \\
\hline 29-Aug-19 & $2,044.18$ \\
\hline 30-Aug-19 & $2,046.03$ \\
\hline
\end{tabular}

From Figure 9, it is cleared that AMZN stock prices increasing day by day, that is why graph is presenting trending scenario. Prediction give estimation idea of future, by analyzing prediction results people can value their business.

\subsection{Time Series Forecasting method for AAPL Stock Market Prediction}

For time series forecasting method, we used AAPL Stock market data from Jan 2019 to July 2019. The data was obtained from yahoo finance and before stock market prediction measurements; we applied some preprocessing to organize data for better prediction results. We converted each month into three quarters, one quarter was ten days and total thirty days for each month become equal to 1,2,3 values. Now we can say for seven months there was considered 21 days or 21 quarters. For each quarter, we obtained average of ten working stock market days.

Now let us examine the AAPL data before and after preprocessing.

Table 8: General representation of AAPL data from yahoo finance

\begin{tabular}{|c|r|r|r|r|r|r|}
\hline \multicolumn{1}{|c|}{ Date } & \multicolumn{1}{c|}{ Open } & \multicolumn{1}{c|}{ High } & \multicolumn{1}{c|}{ Low } & \multicolumn{1}{c|}{ Close } & \multicolumn{1}{c|}{ Adj Close } & \multicolumn{1}{c|}{ Volume } \\
\hline 2-Jan-19 & 154.89 & 158.85 & 154.23 & 157.92 & 156.6424 & 37039700 \\
\hline 3-Jan-19 & 143.98 & 145.72 & 142 & 142.19 & 141.0396 & 91312200 \\
\hline 4-Jan-19 & 144.53 & 148.55 & 143.8 & 148.26 & 147.0605 & 58607100 \\
\hline 7-Jan-19 & 148.7 & 148.83 & 145.9 & 147.93 & 146.7332 & 54777800 \\
\hline 8-Jan-19 & 149.56 & 151.82 & 148.52 & 150.75 & 149.5304 & 41025300 \\
\hline 9-Jan-19 & 151.29 & 154.53 & 149.63 & 153.31 & 152.0697 & 45099100 \\
\hline 10-Jan-19 & 152.5 & 153.97 & 150.86 & 153.8 & 152.5557 & 35780700 \\
\hline 11-Jan-19 & 152.88 & 153.7 & 151.51 & 152.29 & 151.0579 & 27023200 \\
\hline 14-Jan-19 & 150.85 & 151.27 & 149.22 & 150 & 148.7864 & 32439200 \\
\hline 15-Jan-19 & 150.27 & 153.39 & 150.05 & 153.07 & 151.8316 & 28710900 \\
\hline 16-Jan-19 & 153.08 & 155.88 & 153 & 154.94 & 153.6865 & 30569700 \\
\hline 17-Jan-19 & 153.08 & 155.88 & 153 & 154.94 & 153.6865 & 30569700 \\
\hline 18-Jan-19 & 153.08 & 155.88 & 153 & 154.94 & 153.6865 & 30569700 \\
\hline 19-Jan-19 & 153.08 & 155.88 & 153 & 154.94 & 153.6865 & 30569700 \\
\hline - & - & - & - & - & - & - \\
\hline 25-Jul-19 & 208.89 & 209.24 & 206.73 & 207.02 & 207.02 & 13909600 \\
\hline 26-Jul-19 & 207.48 & 209.73 & 207.14 & 207.74 & 207.74 & 17601200 \\
\hline
\end{tabular}

M Umer Ghani, M Awais and Muhammad Muzammul Stock Market Prediction Using Machine Learning(ML)Algorithms
ADCAIJ: Advances in Distributed Computing and Artificial Intelligence Journal Regular Issue, Vol. 8 N. 4 (2019), 97-116 eISSN: 2255-2863 - http://adcaij.usal.es Ediciones Universidad de Salamanca - CC BY NC DC 
Only dates and closing prices of stock market AAPL product was our actual need to predict future, then we considered stock values as follow

Table 9: AAPL data before and after preprocessing

\begin{tabular}{|c|c|}
\hline \multicolumn{2}{|c|}{$\begin{array}{l}\text { Used AAPL data for predictions } \\
\text { Data before preprocessing }\end{array}$} \\
\hline Date & Close \\
\hline 2-Jan-19 & 157.92 \\
\hline 3-Jan-19 & 142.19 \\
\hline 4-Jan-19 & 148.26 \\
\hline 7-Jan-19 & 147.93 \\
\hline 8-Jan-19 & 150.75 \\
\hline 9-Jan-19 & 153.31 \\
\hline 10-Jan-19 & 153.8 \\
\hline 11-Jan-19 & 152.29 \\
\hline 14-Jan-19 & 150 \\
\hline 15-Jan-19 & 153.07 \\
\hline 16-Jan-19 & 154.94 \\
\hline- & - \\
\hline- & - \\
\hline 25-Jul-19 & 207.02 \\
\hline 26-Jul-19 & 207.74 \\
\hline & \\
\hline & \\
\hline & \\
\hline & \\
\hline & \\
\hline & \\
\hline & \\
\hline & \\
\hline & \\
\hline
\end{tabular}

\begin{tabular}{|c|c|c|c|}
\hline \multicolumn{4}{|c|}{$\begin{array}{l}\text { Used AAPL data for predictions } \\
\text { Data after preprocessing }\end{array}$} \\
\hline $\mathbf{T}$ & Month & Quarter & Close Price \\
\hline 1 & January & 1 & 150.59 \\
\hline 2 & & 2 & 153.83 \\
\hline 3 & & 3 & 157.54 \\
\hline 4 & February & 1 & 171.26 \\
\hline 5 & & 2 & 170.67 \\
\hline 6 & & 3 & 173.43 \\
\hline 7 & March & 1 & 174.38 \\
\hline 8 & & 2 & 184.26 \\
\hline 9 & & 3 & 189.83 \\
\hline 10 & April & 1 & 196.69 \\
\hline 11 & & 2 & 200.55 \\
\hline 12 & & 3 & 204.86 \\
\hline 13 & May & 1 & 205.44 \\
\hline 14 & & 2 & 187.72 \\
\hline 15 & & 3 & 178.63 \\
\hline 16 & Jun & 1 & 183.90 \\
\hline 17 & & 2 & 195.69 \\
\hline 18 & & 3 & 198.40 \\
\hline 19 & July & 1 & 202.49 \\
\hline 20 & & 2 & 203.77 \\
\hline 21 & & 3 & 207.90 \\
\hline 22 & August & 1 & \\
\hline 23 & & 2 & \\
\hline 24 & & 3 & \\
\hline
\end{tabular}

In Table 9, there is present on month as august without values that will be predicted after all type of time series forecasting process. As we divided each month into three quarters then the approach that need to be predict is august three quarters. We will perform different processing methods for the finding of different forecasting values. Before further processing let's consider graphical representation of data after preprocessing.

M Umer Ghani, M Awais and Muhammad Muzammul Stock Market Prediction Using Machine Learning(ML)Algorithms
ADCAIJ: Advances in Distributed Computing and Artificial Intelligence Journal Regular Issue, Vol. 8 N. 4 (2019), 97-116 elSSN: 2255-2863 - http://adcaij.usal.es Ediciones Universidad de Salamanca - CC BY NC DC 


\subsubsection{Graphical representation of data after preprocessing}

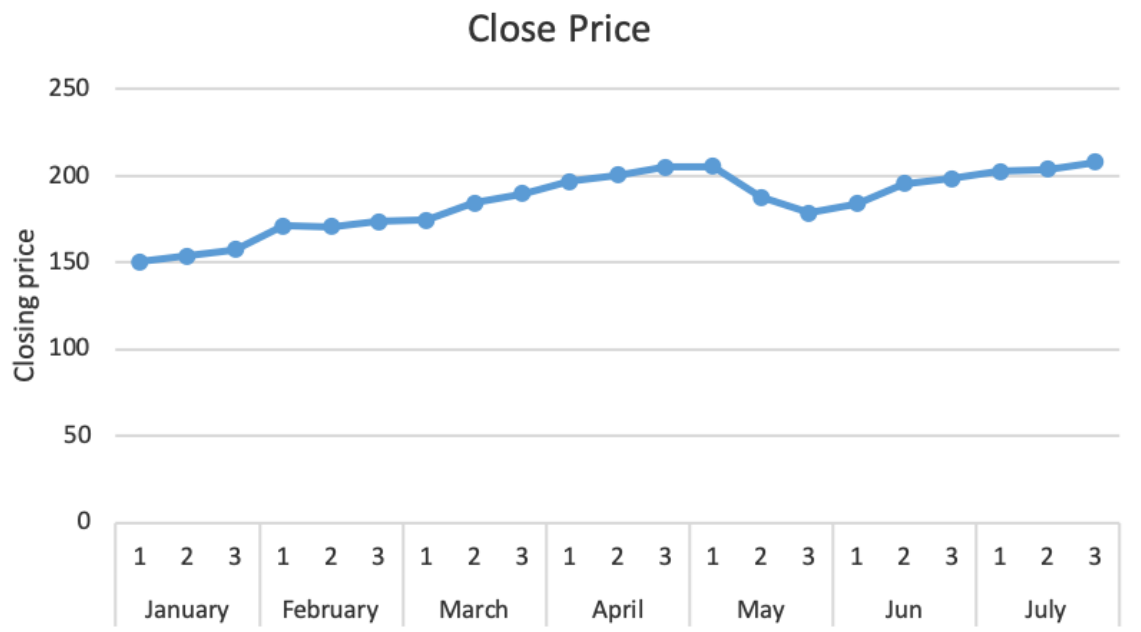

Figure 10: Quarter based graphical data representation for AAPL data.

Now according to Fig 10 each month is represented by three dots and we can say it is one quarter. For further quarter consideration all data is present in Table 9. If we consider this graph there is no regularity in data some time it's going straight sometime its going up sometime its going down then we can say there is no presence of seasonality.

Seasonality can be considered when continuously data changing with a trend in each month. As we divided each month into three quarters with each quarter of ten days now let's consider moving average with MA(3). For each quarter value of MA can be considered as average of three quarters used in each month.

For first value the required result for MA can be predicted with average of $1,2,3=2^{\text {nd }}$ value of the month, similarly we can find out all other patterns for whole data by using MS excel.

\subsubsection{MA values for closing prices with AAPL stock data}

Table 10: MA values for closing prices with AAPL stock data

\begin{tabular}{|c|c|c|c|c|}
\hline $\mathrm{T}$ & Month & Quarter & Close Price & MA(3) \\
\hline 1 & January & 1 & 150.59 & \\
\hline 2 & & 2 & 153.83 & 153.99 \\
\hline 3 & & 3 & 157.54 & 160.88 \\
\hline 4 & February & 1 & 171.26 & 166.49 \\
\hline 5 & & 2 & 170.67 & 171.79 \\
\hline 6 & & 3 & 173.43 & 172.83 \\
\hline 7 & March & 1 & 174.38 & 177.36 \\
\hline 8 & & 2 & 184.26 & 182.82 \\
\hline 9 & & 3 & 189.83 & 190.26 \\
\hline 10 & April & 1 & 196.69 & 195.69 \\
\hline 11 & & 2 & 200.55 & 200.70 \\
\hline
\end{tabular}

M Umer Ghani, M Awais and Muhammad Muzammul Stock Market Prediction Using Machine Learning(ML)Algorithms
ADCAIJ: Advances in Distributed Computing and Artificial Intelligence Journal Regular Issue, Vol. 8 N. 4 (2019), 97-116 elSSN: 2255-2863 - http://adcaij.usal.es Ediciones Universidad de Salamanca - CC BY NC DC 


\begin{tabular}{|c|c|c|c|c|}
\hline $\mathrm{T}$ & Month & Quarter & Close Price & MA(3) \\
\hline 12 & & 3 & 204.86 & 203.62 \\
\hline 13 & May & 1 & 205.44 & 199.34 \\
\hline 14 & & 2 & 187.72 & 190.60 \\
\hline 15 & & 3 & 178.63 & 183.42 \\
\hline 16 & Jun & 1 & 183.90 & 186.08 \\
\hline 17 & & 2 & 195.69 & 192.67 \\
\hline 18 & & 3 & 198.40 & 198.86 \\
\hline 19 & July & 1 & 202.49 & 201.55 \\
\hline 20 & & 2 & 203.77 & 204.72 \\
\hline 21 & & 3 & 207.90 & 205.83 \\
\hline 22 & August & 1 & & \\
\hline 23 & & 2 & & \\
\hline 24 & & 3 & & \\
\hline
\end{tabular}

In Table 10, MA is considered as central value of three quarters of a month. Now let us consider other terms for this data that completely represented in Table 11. Before the presentation of other terms we will consider there meanings and use in whole process.

Let us now consider central moving average of three quarters of a month with CMA(3). CMA is considered as center of two MA values for first moth and it can be said as central value of MA values in three quarters of a month.

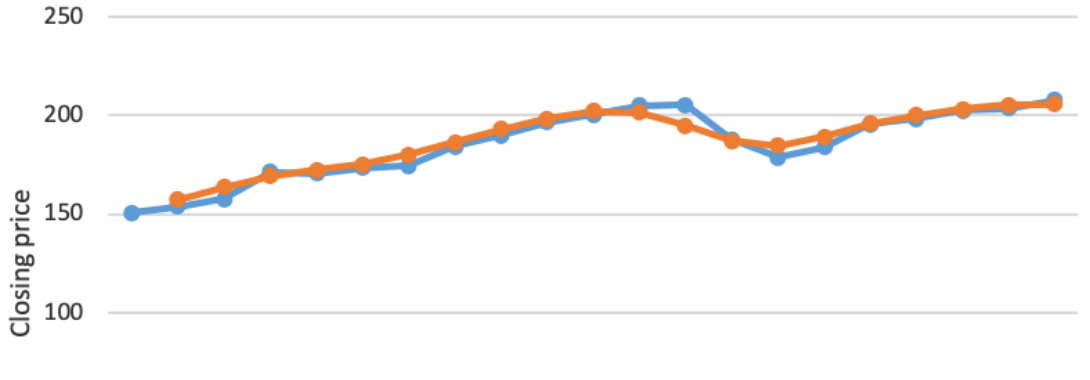

50

0

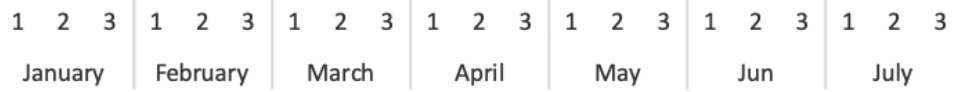

Figure 11: Line graph for actual closing and predicted central moving average (CMA).

In Fig 11, blue line representing actual closing prices and orange line representing predicted central moving average CMA(3) values that can be checked in Table 17.

Now for further accuracy and other parameters finding we will do more steps. Next step is called smoothing, for this purpose we need two variables one is called sessional component $\left(\mathrm{S}_{t}\right)$ and other is called irregular component $\left(\mathrm{I}_{t}\right)$ final result for smoothing can be considered by product of both of these variables $\left(\mathrm{S}_{\mathrm{t}} \mathrm{I}_{\mathrm{t}}\right)$.

M Umer Ghani, M Awais and Muhammad Muzammul

Stock Market Prediction Using Machine Learning(ML)Algorithms
ADCAIJ: Advances in Distributed Computing and Artificial Intelligence Journal Regular Issue, Vol. 8 N. 4 (2019), 97-116 elSSN: 2255-2863 - http://adcaij.usal.es Ediciones Universidad de Salamanca - CC BY NC DC 


\section{Smoothing $=$ St It $=$ actual closing price $/$ CMA(3) $\quad$ Eq3}

Let us consider classical model for time series that can be considered as

\section{Actual Close Prices $=$ Yt $=$ St * It * Tt Eq4}

Let us now consider full output by linear regression before further consideration of Time series forecasting. Tt can be obtained by addition of coefficients present in Table 16.1, and then multiplying with $\mathrm{T}$ values as serial number of stock market.

Table 11: Summary output linear regression

\begin{tabular}{|c|c|c|c|c|c|c|}
\hline \multicolumn{7}{|c|}{ SUMMARY OUTPUT LINEAR REGRESSION } \\
\hline \multicolumn{7}{|c|}{ Regression Statistics } \\
\hline \multicolumn{4}{|l|}{ Multiple R } & 0.810585 & & \\
\hline \multicolumn{4}{|l|}{ R Square } & 0.657048 & & \\
\hline \multicolumn{4}{|c|}{ Adjusted R Square } & 0.637995 & & \\
\hline \multicolumn{4}{|c|}{ Standard Error } & 9.829845 & & \\
\hline \multicolumn{4}{|c|}{ Observations } & 20 & & \\
\hline & $d f$ & $S S$ & $M S$ & $F$ & Significance F & \\
\hline Regression & 1 & 3332.184 & 3332.184 & 34.48543 & & $1.47 \mathrm{E}-05$ \\
\hline Residual & 18 & 1739.265 & 96.62585 & & & \\
\hline Total & 19 & 5071.449 & & & & \\
\hline
\end{tabular}

Table 11.1: Time series forecasting summary with output results

\begin{tabular}{|c|c|c|c|c|c|c|c|}
\hline & Coefficients & Standard Error & $P$-value & Lower 95\% & Upper 95\% & Lower 95.0\% & Upper 95.0\% \\
\hline Intercept & 162.6366 & 4.903824 & $1.36 \mathrm{E}-17$ & 152.3341 & 172.93918 & 152.3341 & 172.9392 \\
\hline $\mathbf{1}$ & 2.238482 & 0.381185 & $1.47 \mathrm{E}-05$ & 1.437642 & 3.0393223 & 1.437642 & 3.039322 \\
\hline
\end{tabular}

Seasonality and irregularity components tell about the distance closeness or away position from actual price line of graph. $\mathrm{S}_{\mathrm{t}}$ in Table 17 is sessional component, let us consider its method of working. Now let us consider depersonalize values for data, this can be done actual prices $\left(\mathrm{Y}_{\mathrm{t}} / \mathrm{S}_{\mathrm{t}}\right.$ that is also necessary for stock values prediction. Now for forecasting we can obtain results of our predictions by dividing seasonality with $\mathrm{T}_{\mathrm{t}}$, that is considered our actual prediction obtained from whole process. Below is the obtained components table that is obtained by methodology for stock values prediction of AAPL stock for next month that is represented by yellow color.

Table 12: Time series forecasting with predicted stock prices for next month august

\begin{tabular}{|c|c|c|c|c|c|c|}
\hline Month & CMA(3) & $S_{t} I_{t}$ & $S_{t}$ & DESEZ & $\mathbf{T}_{\mathbf{t}}$ & Forecasting Predicted prices \\
\hline January & & & 1.00 & 150.59 & 164.88 & 164.88 \\
\hline & 157.43 & 0.98 & 0.99 & 155.38 & 167.11 & 165.44 \\
\hline & 163.68 & 0.96 & 0.99 & 159.14 & 169.35 & 167.66 \\
\hline
\end{tabular}

M Umer Ghani, M Awais and Muhammad Muzammul Stock Market Prediction Using Machine Learning(ML)Algorithms
ADCAIJ: Advances in Distributed Computing and Artificial Intelligence Journal Regular Issue, Vol. 8 N. 4 (2019), 97-116 elSSN: 2255-2863 - http://adcaij.usal.es Ediciones Universidad de Salamanca - CC BY NC DC 


\begin{tabular}{|c|c|c|c|c|c|c|}
\hline Month & CMA(3) & $S_{t} I_{t}$ & $S_{t}$ & DESEZ & $\mathbf{T}_{\mathbf{t}}$ & Forecasting Predicted prices \\
\hline February & 169.14 & 1.01 & 1.00 & 171.26 & 171.59 & 171.59 \\
\hline & 172.31 & 0.99 & 0.99 & 172.39 & 173.83 & 172.09 \\
\hline & 175.09 & 0.99 & 0.99 & 175.19 & 176.07 & 174.31 \\
\hline March & 180.09 & 0.97 & 1.00 & 174.38 & 178.31 & 178.31 \\
\hline & 184.75 & 0.97 & 0.99 & 180.43 & 196.21 & 194.25 \\
\hline Jun & 189.37 & 0.97 & 1.00 & 183.90 & 198.45 & 198.45 \\
\hline & 195.76 & 1.00 & 0.99 & 197.67 & 200.69 & 198.68 \\
\hline & 200.21 & 0.99 & 0.99 & 200.40 & 202.93 & 200.90 \\
\hline July & 203.13 & 1.00 & 1.00 & 202.49 & 205.17 & 205.17 \\
\hline & 205.27 & 0.99 & 0.99 & 205.82 & 207.41 & 205.33 \\
\hline & 205.83 & 1.01 & 0.99 & 210.00 & 209.64 & 207.55 \\
\hline August & & & 1.00 & & 211.88 & 211.88 \\
\hline & & & 0.99 & & 214.12 & 211.98 \\
\hline & & & 0.99 & & 216.36 & 214.20 \\
\hline
\end{tabular}

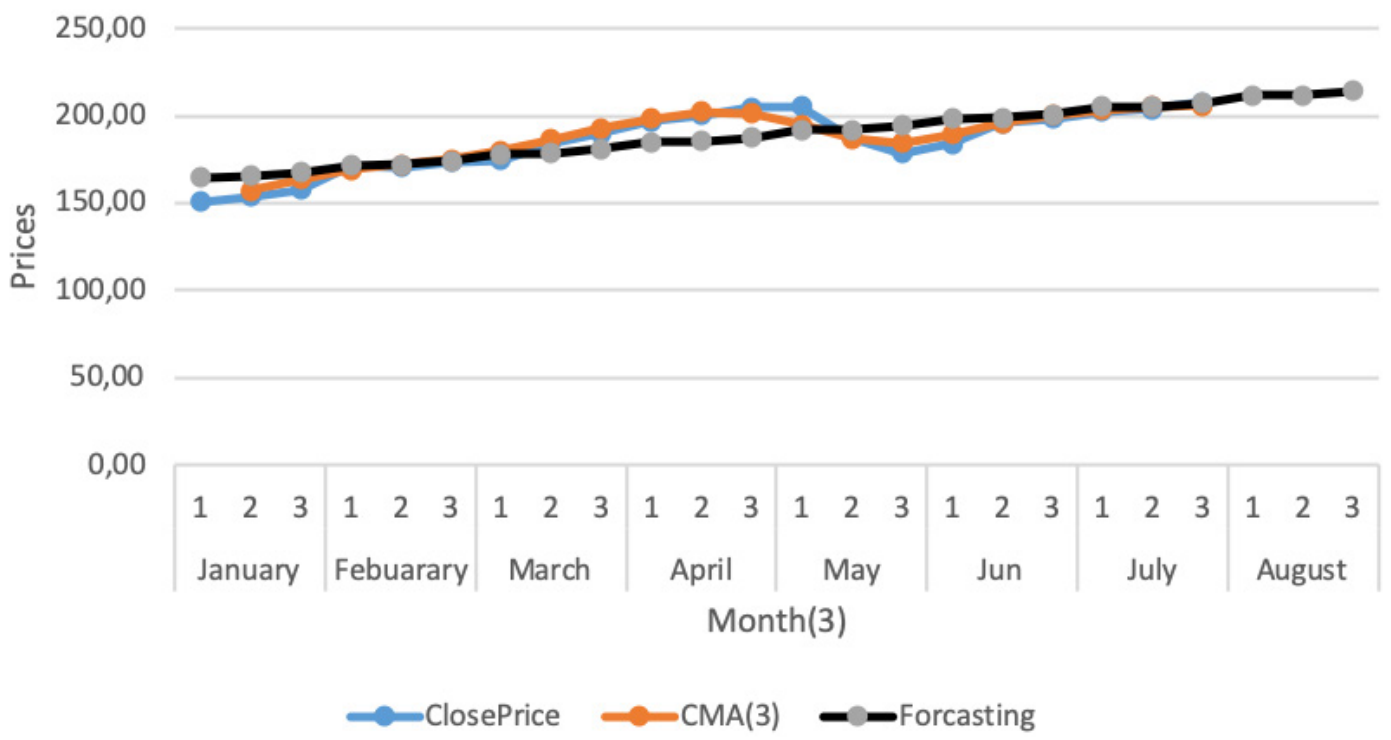

Figure 12: Graphical representation of actual and predicted stock prices for AAPL.

\section{Conclusion}

Stock market prediction is actual demand for beneficial business. Predictions always helpful to decrease risk factor in any business environment. Risk factor can be analyzed on the basis of historical data and previous business trends. This research based on several results and we used machine learning algorithm (ML) as Linear Regression (LR) with respect relations to business priority. Linear regression applied on different data sets that were obtained

M Umer Ghani, M Awais and Muhammad Muzammul Stock Market Prediction Using Machine Learning(ML)Algorithms
ADCAIJ: Advances in Distributed Computing and Artificial Intelligence Journal Regular Issue, Vol. 8 N. 4 (2019), 97-116 elSSN: 2255-2863 - http://adcaij.usal.es Ediciones Universidad de Salamanca - CC BY NC DC 
from stock market place (Yahoo finance). Yahoo Finance ever considered as best market place for obtaining stock market data about any product. In our research we used Amazon (AMZN) and Apple (AAPL) datasets for our practical approaches. Before applying ML on datasets, we analyzed stock market trends for both products. Trend analysis also provide predictions about future business plan. In next step first we used AMZN dataset and after analysis of stock market trend we applied linear regression with the help of Excel statistical graphs. Secondly, we applied three month moving average(3MMA) method to predict stock market prices of AMZN products. Thirdly we applied exponential smoothing (ES) for predictions. After comparing all results, we obtained hypothesis that exponential smoothing prediction results given less error and greater accuracy and we considered it best stock market predictor with general trend analysis. Similarly, we applied these three methods on AAPL data and obtained results about predictions. After applying these methodologies, we capable to predict one-month forward stock market trend and we presented August prices as founded throughput. At end of previous chapter, we applied Time Series Forecasting methodology and predicted AAPL stock prices for next month. Time Series Forecasting method also introduced new ways for stock market trend analysis. At last we can say by applying this research methodology we are able to predict future stock market trends easily. Several Machine learning algorithms can be used for stock market prediction but in this research we used few algorithms like Linear regression(LR), Three Months Moving Average(3MMA) and Exponential Smoothing and if we further consider many other algorithms can also be used for Stock Market Prediction(SMP).In Whole research we found Exponential Smoothing predictions results are best rather than Linear Regression(LR) and Three Months Moving Average(3MMA).

\section{References}

Tae Kyun Lee et al. "Global stock market investment strategies based on financial network indicators using machine learning tech niques", Expert Systems with Applications, 117(2019):228-242.

Bruno et al. "Literature review: Machine learning techniques applied to financial market prediction", Expert Systems with Applications, 124(2019): 226-251.

Thomas Fischer et al. "Deep learning with long short-term memory networks for financial market predictions", European Journal of Operational Research, 270.2(2018): 654-669.

Kang Zhang et al. "Stock Market Prediction Based on Generative Adversarial Network", Procardia Computer Science, 147(2019):400-406

Ben Moews et at. "Lagged correlation-based deep learning for directional trend change prediction in financial time series". Expert Systems with Applications, 120(2019):197-206.

Fische Mospel et al. "Deep learning with machine learning algorithms for financial market predictions", European Journal of scientific Research, 220.2(2019):654-669.

Markku Karhunen et al. "Algorithmic sign prediction and covariate selection across eleven international stock markets”, Expert Systems with Applications, 115(2019):256-263.

Eunsuk Chong et at. "Deep learning networks for stock market analysis and prediction: Methodology, data representations, and case studies", Expert Systems with Applications,8 (2017): 187-205.

WangQili et al. "Combining the wisdom of crowds and technical analysis for financial market prediction using deep random subspace ensembles", Neurocomputing, 299(2018):51-61.

ChangjuLee et al. "Explaining future market return and evaluating market condition with common preferred spread index", Physica A: Statistical Mechanics and its Applications, 220(2019):220-229.

$\mathrm{Mu}-$ YenChen et al. "Modeling public mood and emotion: Stock market trend prediction with anticipatory computing approach", Computers in Human Behavior (2018).

Hiransha et al. "NSE Stock Market Prediction Using Deep-Learning Models", Procedia Computer Science, 132(2018): 1351-1362.

FengmeiYang et al. "A novel hybrid stock selection method with stock prediction", Applied Soft Computing (2019).

Yue-gang Song et al.Corrigendum to "Towards a new approach to predict business performance using machine learning” [Cogn. Syst. Res. 52 (2018): 1004-1012].

M Umer Ghani, M Awais and Muhammad Muzammul

Stock Market Prediction Using Machine Learning(ML)Algorithms
ADCAIJ: Advances in Distributed Computing and Artificial Intelligence Journal Regular Issue, Vol. 8 N. 4 (2019), 97-116 elSSN: 2255-2863 - http://adcaij.usal.es Ediciones Universidad de Salamanca - CC BY NC DC 